\title{
Phylogenetic Analysis of 28S rRNA Gene of Indigenous Xiphinema pachydermum
}

\author{
Anju Sharma*, Satish K. Sharma, Kiran Rana and Anil Kumar Verma \\ Dr. Y S Parmar University of Horticulture and Forestry, Nauni, Solan \\ Himachal Pradesh-173230, India \\ *Corresponding author
}

\begin{tabular}{|l|}
\hline Ke y w o r d s \\
Phylogenetic trees, \\
$\begin{array}{l}\text { Strawberry, } \\
\text { Xiphinema } \\
\text { pachydermum }\end{array}$ \\
\hline Article Info \\
\hline $\begin{array}{l}\text { Accepted: } \\
\text { 15 June } 2019 \\
\text { Available Online: } \\
\text { 10 July } 2019\end{array}$ \\
\hline
\end{tabular}

\section{Introduction}

Plant parasitic nematodes are widely distributed in all types of habitats and pose
A B S T R A C T

An attempt has been made to determine the phylogenetic relationship to trace out the evolutionary pattern of the test sequence of Xiphinema pachydermum partial $28 \mathrm{~S}$ rRNA gene and to find out relationship of the same with other selected sequences of NCBI by constructing phylogenetic trees. Nucleotide sequence of $28 \mathrm{~S}$ ribosomal RNA gene of Xiphinema pachydermum from Solan, Himachal Pradesh (AM779749.1) showed maximum homology of 93\% with Xiphinema inaequale isolate HP 28S large subunit ribosomal RNA gene, partial sequence (HM163210.1) from Baijnath, Himachal Pradesh. The pairwise similarity score of 38 nucleotide sequences with test sequence elucidated 90-93\% sequence identity with other sequences from India. Sequences from South Africa showed 91\% identity with the test sequence while sequences from Brazil, Czech Republic, Japan, China and Slovakia showed 90\% similarity. USA, Italy, Portugal, Spain, and Canada depicted $89 \%$ sequence homology with the Solan isolate. Multiple sequence alignment of 38 selected sequences of Xiphinema species having similarity score between 89 to 93 percent was performed using Clustal Omega and its output was used in Phylip 3.695 for constructing phylograms. The test sequence, AM779749.1 showed maximum closeness with another Indian isolate from Himachal Pradesh, HM163210.1 (Xiphinema inaequale) at significant bootstrap values of 100 both by Neighbor Joining and Maximum Parsimony methods respectively, which are further in close proximity to cluster of sequences containing another isolate from Himachal Pradesh, HM163211.1 (Xiphinema lambertii isolate XL 28S large subunit ribosomal RNA gene, partial sequence). While close proximity to the sequences from Czech Republic, Slovakia, and Italy, however having low bootstrap value may depict that insect might have migrated from Central Europe to India or vice versa. The predicted molecular weight of deduced amino acid sequence was 6031.69Da and was found to be rich in glycine $(13.6 \%)$, serine (13.6\%), alanine (11.9\%), proline (10.2\%) and aspartic acid (8.5\%). serious threat to the production of horticultural and agricultural crops. Xiphinema species, among the longidorids, are known nematode vectors of several plant viruses and play a vital 
role in transmission of diseases, which leads to either total loss of crops or reduction in yield and quality of the product. Strawberry is one of the major fruit crops which is highly infested by a number of plant parasitic nematode species directly or in association with microorganisms. A virus transmitting nematode named Xiphinema pachydermum (infecting strawberry in Himachal Pradesh) with was procured and partial 28S rRNA gene (Verma, 2007) was isolated and sequenced (NCBI Accession Number AM779749) followed by in silico analysis useful for numerous applications to obtain a better understanding of both patterns and processes of evolution. During the systematic survey conducted for the prevalence of virus transmitting nematodes in association with strawberry at Solan, Sirmaur, Kangra, Una, Bilaspur, Hamirpur, Chamba, Mandi and Kullu districts of Himachal Pradesh revealed the presence of Xiphinema species among the longiroids prevalent in the rhizosphere of strawberry plants (Verma and Luqman Khan, 2012).

\section{Test sequence}

>AM779749.1 Xiphinema pachydermum partial 28S rRNA gene, isolate 1

TTTGAACGAAGGCTGCGAGATCTGAGA CNTTCGAGCTANAAGAAANGGACGGA ACCGTCTGACGCCCTCG

GGAATCAGTCGAACGACGCGCGAACG CGTCTCGATCGTCGGAGCGTAAAAGTC CGGCTCGAGGCGTCTAG

TAGTCGCGTTCGTAAGGCGCATTTCTC GAGGGTTAGCGCCGCGACCGATGCGAA CGGCCGACGACGCCGG

CGAGTTGAGGTCGAACGCCCTTCGCGG GTATTCGTAACCAGCTCGTTCGGTAGA TATTGTCGGATCTCTA
TTAATTAAGCATCGAGCGAATGACTAT CAAATACGTCGGCGTAAAACGCTCGAC GAGCGGGGGAGATTCG

GCCGGTCTTACGGTACGTGCTCGCGGG TTCTCGTTCGGCGCGGGATCTTTTCCCG ATGACCCCTTGGACG

CTACCGCGTCTAAGGCGTCCGCGGGGC CCGAGTCGCCCCCCCGTCCTGATTGGT GTTGAAACCCGTATGA

TGGAGTCTAAGCGTTAGAGCTAAGATT TTGCCCTGCCAAAGGCTGTATCCGGGA AAAAGGGAAAAGGTGG

TGCCCCTGACTGCCGAGGGGCGGTTCC GTGCGTTTCCCGGCGGGGGGTGGGGTT TGGCCGTGGACTGTAC

AGGAGGCTGTTGTGGTTTTAATTATTA AGACCCTTCCGCTTGCGGTGAGGTTAC TAATGGGTGACGTTTT

CGTGGGCTGGGGGTGGCCCAGTGTAAA GTATGTGTGGGGTGGGCGCAATCGGTT CCCGTGGTTCTCGTGC

\section{TGCGGGTTTGGTCTTGGATGAGGTGAG CTTTATTCAGTTTTGA}

Therefore, in the present study, an attempt has been made to determine the phylogenetic relationship (Nei and Kumar, 2000)

To trace out the evolutionary pattern of the test sequence of Xiphinema pachydermum partial 28S rRNA gene and to find out relationship of the same with other selected sequences of NCBI.

\section{Materials and Methods}

Various physical and chemical parameters (https://web.expasy.org/protparam/) including amino acid content calculation were 
performed to know more about the protein test sequence by using the ProtParam package of the ExPASy web server (http://www.expasy.ch/tools/protparam.html) and the secondary structure was predicted by using SOPMA (http://npsa-pbil.ibcp.fr/cgibin/npsa_automat.pl?page=npsa_sopma.html) tool. Phylogenetic trees were constructed using Maximum Parsimony and Neighbor Joining (Saitou and Nei, 1987; Tamura et al., 2004) methods using Phylip 3.695 (the PHYLogenyInference Package, http://evolution.genetics.washington.edu/phyli p.html). The bootstrap consensus tree inferred from 500 replicates (Felsenstein, 1985) is taken to represent the evolutionary history of the taxa analysed. Nucleotide sequence of $28 \mathrm{~S}$ ribosomal rna gene of Xiphinema pachydermum from Solan, Himachal Pradesh (AM779749.1) was compared with other sequences of Xiphinema species retrieved from NCBI database using BLAST (Altschul et al., 1990). Table 1 shows the percent homology of Xiphinema pachydermum 28SrRNA gene with other Xiphinema species.

\section{Results and Discussion}

\section{Translation of Xiphinema pachydermum 28S rRNA gene}

The nucleotide test sequence AM779749.1 of 813 bp was translated using Expasy Translate tool and a protein sequence of 59AA with largest ORF was obtained for further analysis, the FASTA format of which is as given below: > VIRT-62476:5'3' Frame 3, start_pos=99

MTIKYVGVKRSTSGGDSAGLTVRARGFS FGAGSFPDDPLDATASKASAGPESPPRPD WC

Physical and chemical parameters of deduced amino acid sequence of Xiphinema pachydermum 28S rRNA gene

Various physical and chemical parameters viz., molecular weight (6031.69), theoretical
pI (7.92), amino acid composition, atomic composition, instability index (41.04), aliphatic index (46.44) and grand average of hydropathicity $(-0.420)$ were obtained for the deduced protein sequence of Xiphinema pachydermum $28 \mathrm{~S}$ rRNA gene. The instability index indicated that the protein is unstable. The deduced protein sequence was found to be rich in glycine (13.6\%), serine (13.6\%), alanine $(11.9 \%)$, proline $(10.2 \%)$ and aspartic acid $(8.5 \%)$. The percentage of arginine and threonine was $6.8 \%$ and while that of lysine, phenylalanine and valine was $5.1 \%$. It was found to be deficient in leucine $(3.4 \%)$, and cysteine, glutamic acid, isoleucine, methionine, tryptophan and tyrosine with one count only (Table 2). Rest of the amino acids were absent. Total number of negatively (Asp + Glu) and positively (Arg + Lys) charged residues were found to be 6 and 7 respectively. Total number of atoms were found to be 831 and the chemical formula was obtained as $\mathrm{C}_{262} \mathrm{H}_{407} \mathrm{~N}_{75} \mathrm{O}_{85} \mathrm{~S}_{2}$. The atomic composition showed 262, 407, 75, 85 and 2 atoms of Carbon, Hydrogen, Nitrogen, oxygen and sulphur respectively. The exact mass of the protein sequence was deduced using the Isotopident package of the ExPASy web server (http://education.expasy.org/student projects/isotopident/htdocs/). The monoisotopic mass and the exact mass calculated were found to be 6027.927and 6029.934Da. The probability of combination was $74.51 \%$ of predicted mass of $6027 \mathrm{amu}$.

\section{Phylogenetic analysis}

BLASTn showed identity of query sequence with other isolates of Xiphinema species. The test sequence showed maximum homology of 93\% with Xiphinema inaequale isolate HP 28S large subunit ribosomal RNA gene, partial sequence (HM163210.1) from Baijnath, Himachal Pradesh. The pairwise similarity score of 38 nucleotide sequences with test sequence elucidates 90-93\% sequence identity with other sequences from 
India. Sequences from South Africa showed 91\% identity with the test sequence while sequences from Brazil, Belgium, Czech Republic, Japan, China and Slovakia showed 90\% similarity. USA, Italy, Portugal, Spain, and Canada depicted $89 \%$ sequence homology with the Solan isolate.

Multiple sequence alignment of 38 selected sequences of Xiphinema species having similarity score between 89 to 93 percent was performed using Clustal Omega and its output was used in Phylip3.695 for constructing phylograms. Table 1 shows the list of $28 \mathrm{~S}$ rRNA gene sequences of Xiphinema species retrieved from NCBI. All the nucleotide gene sequences of Xiphinema species when plotted into an evolutionary tree through Neighbor Joining and Maximum Parsimony trees constructed using PHYLIP 3.695 software as shown in Figure 1 and 2 respectively.

Comparative genomic and proteomic phylogenetic analysis of Indian Isolate of partial coat protein gene sequence of Zucchini Yellow Mosaic Virus (ZYMV) has been done with Maximum Likelihood, Neighbor Joining, Maximum Parsimony, and Unweighted pair Group Method of Arithmetic Averages methods using PHYLIP 3.68 by Sharma N et al., (2012). For the validation of phylogenetic trees, "bootstrap" is be used to place confidence intervals on phylogenies (Felsenstein, 1985). It involves resampling points from one's own data, with replacement, to create a series of bootstrap samples of the same size as the original data. Each of these is analyzed, and the variation among the resulting estimates taken to indicate the size of the error involved in making estimates from the original data. In the case of phylogenies, it is argued that the proper method of resampling is to keep all of the original species while sampling characters with replacement, under the assumption that the characters have been independently drawn by the systematist and have evolved independently. Majority-rule consensus trees can be used to construct a phylogeny showing all of the inferred monophyletic groups that occurred in a majority of the bootstrap samples. The Neighbor Joining tree (Fig. 1) constructed using PHYLIP software showed two distinct clades in the phylogenetic tree. The sequence of Xiphinema georgianum from USA branched off early. Most early diverging clade consisted of 11 sequences viz., HM163209.1 (Czech Republic), HM163211.1 (India), AY601603.1 (Italy), AY601602.1 (Slovakia), AY601604.1 (China), AY601601.1 (South Africa), AY601600.1 (South Africa), AY601605.1 (Brazil), JN091972.1 (Japan), AM779749.1 (India) and HM163210.1 (India) including the test sequence with a bootstrap support of 87 . Second big clade consisted of 26 sequences wherein first sub-clade consisted of 5 sequences of Xiphinema floridae with bootstrap value of 100, second sub-clade included 12 sequences with bootstap value of 43 and the third sub-clade was identified with 6 sequences of Xiphinema citricolum from USA and 2 Xiphinema rivesi sequences from Spain, and a Xiphinema santos sequence from Portugal with a bootstrap value of 69 .

The test sequence, AM779749.1 showed maximum closeness with another Indian isolate from Himachal Pradesh, HM163210.1 (Xiphinema inaequale) at significant bootstrap value of 100 by Neighbor Joining method, which are further in close proximity to an isolate from Himachal Pradesh, HM163211.1 (Xiphinema lambertii isolate XL 28S large subunit ribosomal RNA gene, partial sequence) with a bootstrap value of 87 . 
Fig.1 Phylogenetic relationship of Xiphinema pachydermum 28S rRNA gene sequence with other species of Xiphinema by Neighbour Joining method

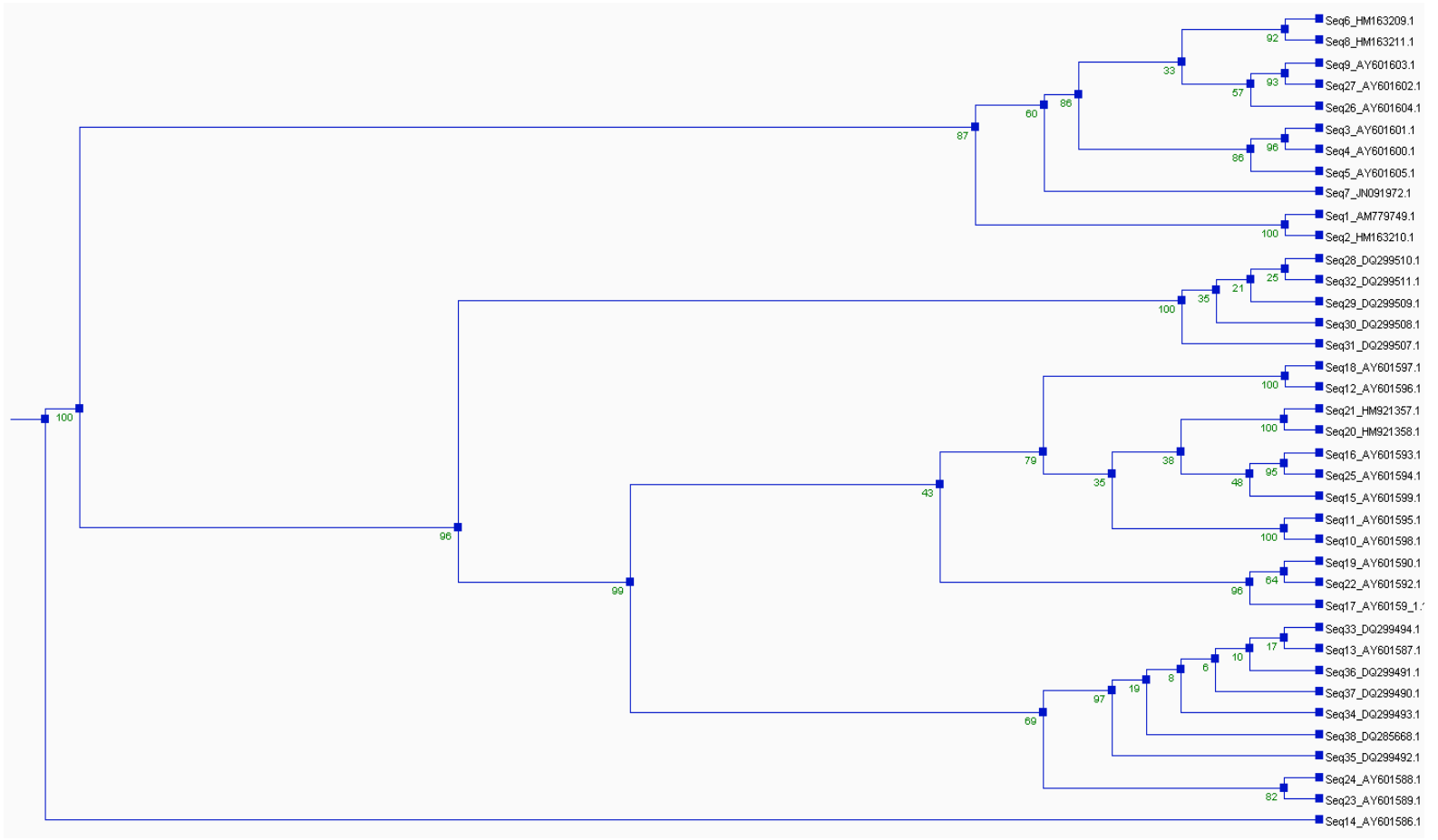

Fig.2 Phylogenetic relationship of Xiphinema pachydermum 28S rRNA gene sequence with other species of Xiphinema by Maximum Parsimony method

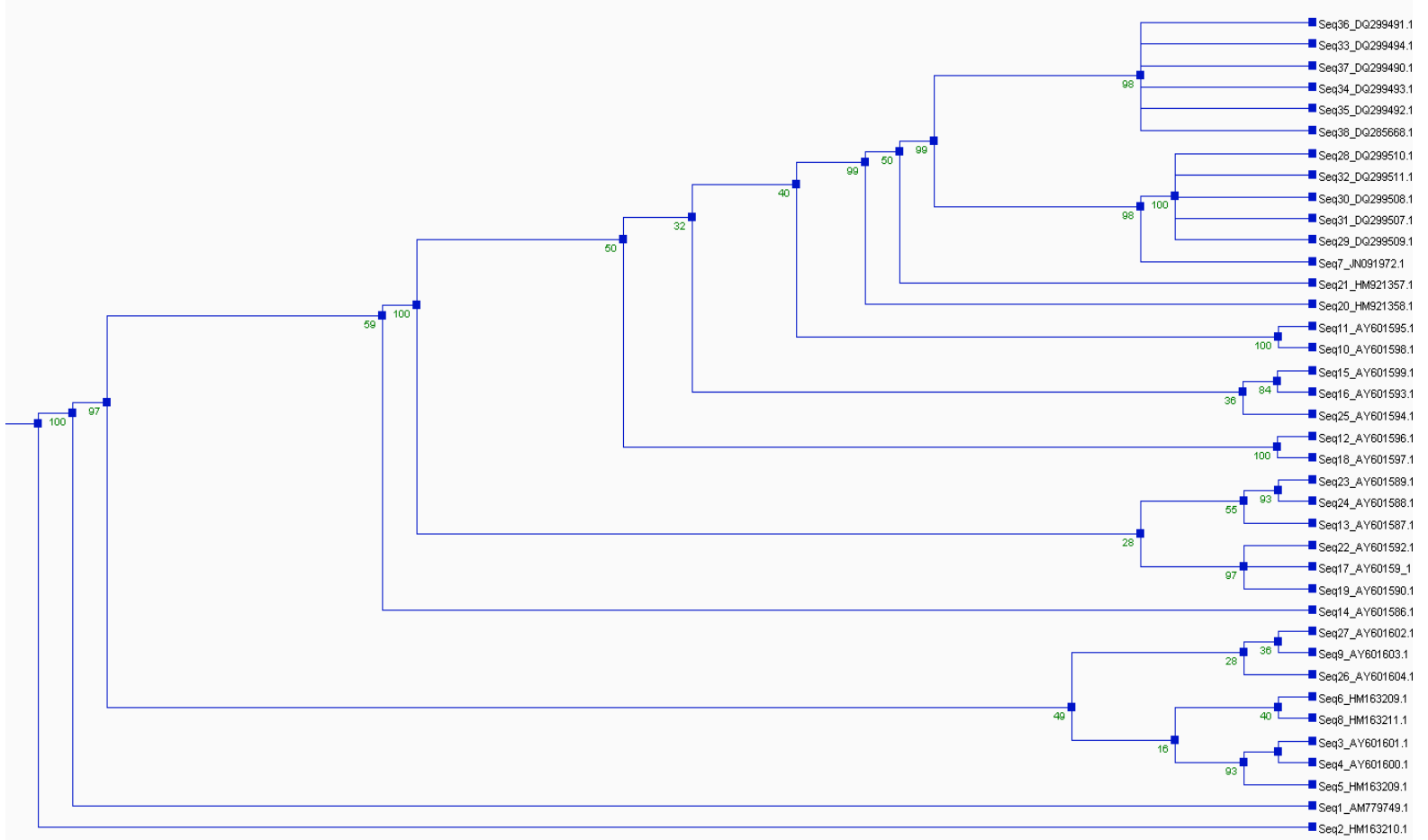


Table.1 List of 28S rRNA gene partial sequences of Xiphinema species retrieved from NCBI

\begin{tabular}{|c|c|c|c|c|c|}
\hline $\begin{array}{l}\text { S. } \\
\text { No. }\end{array}$ & $\begin{array}{l}\text { Accession } \\
\text { Number }\end{array}$ & $\begin{array}{l}\text { DNA } \\
\text { Sequence } \\
\text { Length (bp) }\end{array}$ & Organism & Country & $\begin{array}{l}\text { Maximum } \\
\text { identity }\end{array}$ \\
\hline 1 & AM779749.1 & 813 & Xiphinema pachydermum & Solan, HP, India & $100 \%$ \\
\hline 2 & HM163210.1 & 787 & Xiphinema inaequale & $\begin{array}{l}\text { Baijnath,HP, } \\
\text { India }\end{array}$ & $93 \%$ \\
\hline 3 & AY601601.1 & 770 & Xiphinema brevicollum & South Africa & $91 \%$ \\
\hline 4 & AY601600.1 & 770 & Xiphinema diffusum & South Africa & $91 \%$ \\
\hline 5 & AY601605.1 & 770 & Xiphinema brevicollum & Brazil & $90 \%$ \\
\hline 6 & HM163209.1 & 771 & Xiphinema brevicollum & Czech Republic & $90 \%$ \\
\hline 7 & JN091972.1 & 831 & $\begin{array}{l}\text { Xiphinema americanum group sp. } \\
\text { LZ-2011 }\end{array}$ & Japan & $90 \%$ \\
\hline 8 & HM163211.1 & 773 & Xiphinema lambertii & $\begin{array}{l}\text { Baijnath,HP, } \\
\text { India }\end{array}$ & $90 \%$ \\
\hline 9 & AY601603.1 & 775 & Xiphinema taylori & Italy & $89 \%$ \\
\hline 10 & AY601598.1 & 769 & Xiphinema utahense & USA & $89 \%$ \\
\hline 11 & AY601595.1 & 769 & Xiphinema thornei & USA & $89 \%$ \\
\hline 12 & AY601596.1 & 774 & Xiphinema bricolensis & USA & $89 \%$ \\
\hline 13 & AY601587.1 & 773 & Xiphinema santos & Portugal & $89 \%$ \\
\hline 14 & AY601586.1 & 779 & Xiphinema georgianum & USA & $89 \%$ \\
\hline 15 & AY601599.1 & 771 & Xiphinema americanum & USA & $89 \%$ \\
\hline 16 & AY601593.1 & 771 & Xiphinema thornei & USA & $89 \%$ \\
\hline 17 & AY60159 1.1 & 772 & Xiphinema americanum & USA & $89 \%$ \\
\hline 18 & AY601597.1 & 774 & Xiphinema incognitum & USA & $89 \%$ \\
\hline 19 & AY601590.1 & 773 & Xiphinema pacificum & USA & $89 \%$ \\
\hline 20 & HМ921358.1 & 805 & Xiphinema rivesi & Spain & $89 \%$ \\
\hline 21 & HM921357.1 & 815 & Xiphinema rivesi & Spain & $89 \%$ \\
\hline 22 & AY601592.1 & 772 & Xiphinema californicum & USA & $89 \%$ \\
\hline 23 & AY601589.1 & 768 & Xiphinema rivesi & USA & $89 \%$ \\
\hline 24 & AY601588.1 & 768 & Xiphinema rivesi & USA & $89 \%$ \\
\hline 25 & AY601594.1 & 776 & Xiphinema bricolensis & Canada & $89 \%$ \\
\hline 26 & AY601604.1 & 768 & Xiphinema brevicollum & China & $90 \%$ \\
\hline 27 & AY601602.1 & 773 & Xiphinema taylori & Slovakia & $90 \%$ \\
\hline 28 & DQ299510.1 & 832 & Xiphinema floridae & USA & $89 \%$ \\
\hline 29 & DQ299509.1 & 832 & Xiphinema floridae & USA & $89 \%$ \\
\hline 30 & DQ299508.1 & 832 & Xiphinema floridae & USA & $89 \%$ \\
\hline 31 & DQ299507.1 & 832 & Xiphinema floridae & USA & $89 \%$ \\
\hline 32 & DQ299511.1 & 832 & Xiphinema tarjanense & USA & $89 \%$ \\
\hline 33 & DQ299494.1 & 831 & Xiphinema citricolum & USA & $89 \%$ \\
\hline 34 & DQ299493.1 & 831 & Xiphinema citricolum & USA & $89 \%$ \\
\hline 35 & DQ299492.1 & 831 & Xiphinema citricolum & USA & $89 \%$ \\
\hline 36 & DQ299491.1 & 831 & Xiphinema citricolum & USA & $89 \%$ \\
\hline 37 & DQ299490.1 & 831 & Xiphinema citricolum & USA & $89 \%$ \\
\hline 38 & DQ285668.1 & 831 & Xiphinema citricolum & USA & $89 \%$ \\
\hline
\end{tabular}


Table. 2 Amino acid composition of deduced amino acid sequence of $28 \mathrm{~S}$ rRNA gene of indigenous Xiphinema pachydermum

\begin{tabular}{|l|l|l|l|}
\hline Name & Symbol & Count & Percentage \\
\hline Alanine & Ala(A) & 7 & 11.90 \\
\hline Arginine & Arg (R) & 4 & 6.80 \\
\hline Aspartic Acid & Asp (D) & 5 & 8.50 \\
\hline Cysteine & Cys (C) & 1 & 1.70 \\
\hline $\begin{array}{l}\text { Glutamic } \\
\text { Acid }\end{array}$ & Glu (E) & 1 & 1.70 \\
\hline Glycine & Gly (G) & 8 & 13.6 \\
\hline Isoleucine & Ile (I) & 1 & 1.70 \\
\hline Leucine & Leu (L) & 2 & 3.40 \\
\hline Lysine & Lys (K) & 3 & 5.10 \\
\hline Methionine & Met (M) & 1 & 1.70 \\
\hline Phenylalanine & Phe (F) & 3 & 5.10 \\
\hline Proline & Pro (P) & 6 & 10.20 \\
\hline Serine & Ser (S) & 8 & 13.60 \\
\hline Threonine & Thr (T) & 4 & 6.80 \\
\hline Tryptophan & Trp (W) & 1 & 1.70 \\
\hline Tyrosine & Tyr (Y) & 1 & 1.70 \\
\hline Valine & Val (V) & 3 & 5.10 \\
\hline
\end{tabular}

Sequences from South Africa showed close proximity with a sequence from Brazil as well as with the test sequence with high bootstrap value of 86 . Phylogenetic analysis at nucleotide level further revealed that HM163209.1 (Czech Republic), AY601603.1 (Italy), AY601602.1 (Slovakia), and AY601604.1 (China) with low bootstrap (33), showed close proximity with the test sequence. The sequence of Xiphinema georgianum from USA segregated at a very early stage was found to be most divergent followed by the sequences of Xiphinema citricolum from USA, Xiphinema rivesi from Spain and Xiphinema santos from Portugal.

The Maximum Parsimony (Fig. 2) tree depicted the similar results, as above, showing Xiphinema inaequale sequence to be evolutionarily most similar to the test sequence with a bootstrap value of 100 followed by a group of 8 sequences viz.,
AY601601.1 and AY601600.1 (South Africa), AY601605.1 (Brazil), HM163209.1 (Czech Republic), HM163211.1 (India), AY601603.1 (Italy), AY601604.1 (China) and AY601602.1 (Slovakia), however with low bootstrap value (49) distantly related with sequences of Xiphinema citricolum from USA.

Al-Banna et al., (1997) used nucleotide sequences of the large subunit ribosomal genes (26S rDNA) to examine evolutionary relationships among species of the genus Pratylenchus (Order: Tylenchida, Family: Pratylenchidae), commonly known as rootlesion nematodes. Based on parsimony analyses of approximately 307 aligned nucleotides of the D3 expansion region of the $26 \mathrm{~S}$ rDNA, it is clear that species of Pratylenchus are a paraphyletic assemblage. The outgroup taxon $\mathrm{H}$. belli shares a common ancestor with the clade that includes $P$. vulnus 
and $P$. crenatus while $N$. aberrans and $R$. similis share a common ancestor with 5 other species included in this study.

Morris et al., (2013) sequenced three genes (mtCO1, LSU, and ITS) from nematodes extracted from parasitized Sirex spp. collected inside and outside of the range of $S$. noctilio and assessed phylogenetic relationships among native Deladenus spp. in the northeastern United States and the Kamona strain of D. siricidicola which suggested cospeciation between four North American Sirex spp. and their associated nematode parasites. They discussed nematode-host fidelity in the system and the potential for non-target impacts of a biological control program using $D$. siricidicola against $S$. noctilio.

Using ribosomal (18S, ITS1, ITS2, D2-D3 expansion segments of $28 \mathrm{~S}$ rDNA) and mitochondrial (partial cox1 and nad4) DNA markers in a study of several populations of group from Europe and Morocco, two cryptic species Xiphinema browni sp. n. (formerly reported as Xiphinema pachtaicum) and Xiphinema penevi sp. $\mathrm{n}$. were revealed (Lazarova S et al., 2016). The phylogenetic reconstructions inferred from three molecular markers (18S, D2-D3 28S rDNA and cox1) showed that Xiphinema penevi sp. $\mathrm{n}$. is part of Xiphinema pachtaicum-subgroup and is closely related to Xiphinema incertum, Xiphinema pachtaicum, Xiphinema parapachydermum, Xiphinema plesiopachtaicum, Xiphinema astaregiense and Xiphinema pachydermum. However, phylogenetic relationships of the $X$. americanum-group species reconstructed by Bayesian inference for D2-D3 of 28S rRNA gene sequences did not provide clear species delimitation of the samples studied, although the mtDNA presented interspecific variations useful for demarcation among species (Subbotin S et al., 2016).
From the results obtained it appears that Xiphinema pachydermum sequence of Solan, H.P., India has maximum similarity with Xiphinema inaequale sequence of Baijnath, H.P., India and shares a common ancestor with high bootstrap value. While close proximity to the sequences from $\mathrm{Czech}$ Republic, Slovakia, and Italy, however having low bootstrap value may depict that insect might have migrated from Central Europe to India or vice versa.

\section{References}

Al-Banna L, Williamson V and Gardner S L. Phylogenetic analysis of nematodes of the Genus Pratylenchus using Nuclear 26S rDNA. Molecular Phylogenetics and Evolution. 1997; 7(1): 94-102.

Altschul S F, Gish W, Miller W, Myers E W and Lipman D J. Basic local alignment search tool. Journal of Molecular Biology.1990; 215(3): 403-410

Felsenstein J. Confidence limits on phylogenies: An approach using the bootstrap. Evolution. 1985; 39:783-791.

Lazarova S, Peneva V and Kumari S.Morphological and molecular characterisation, and phylogenetic position of $X$. browni sp. n., X. penevi sp. n. and two known species of Xiphinema americanum-group (Nematoda, Longidoridae). Zookeys. 2016; 574: 1-42

Morris E E, Kepler R M, Long SJ, Williams D W and Hajek A E. Phylogenetic analysis of Deladenus nematodes parasitizing northeastern North American Sirex species. Journal of Invertebrate Pathology. 2013; 113(2): 177-183.

Nei M. and Kumar S. Molecular Evolution and Phylogenetics. 2000. Oxford University Press, New York.

Saitou N. and Nei M. The neighbor-joining method: A new method for 
reconstructing phylogenetic trees. Molecular Biology and Evolution. 1987; 4: 406-425.

Sharma Neha, BhardwajSatyaVrat, Sharma Anju, TomarManica, KaurRajinder, Thakur PritamDass and Handa Anil. Comparative Genomic and Proteomic Phylogenetic Analysis of Indian Isolate of Partial Coat Protein Gene Sequence of Zucchini Yellow Mosaic Virus (ZYMV) Using Data Mining. Journal of Proteomics and Bioinformatics.2012; 5(9): 196-203.

Subbotin S, Chizhov V, DongK, Chitambar J, Orlando V, Bert W and Mollov D. Molecular and morphological characterisation of Xiphinema americanum-group species (Nematoda: Dorylaimida) from California, USA, and other regions, and co-evolution of bacteria from the genus Candidatus Xiphinema tobacter with nematodes. Nematology.2016; 18. 10.1163/15685411-00003012.

Tamura K., Nei M., and Kumar S. Prospects for inferring very large phylogenies by using the neighbor-joining method. Proceedings of the National Academy of Sciences (USA). 2004; 101: 1103011035.

Verma A K.Xiphinema pachydermum partial 28S rRNA gene, isolate 1.GenBankAM 779749.2007.

Verma A K and Khan M L. Description of Xiphinema fragariae N. Sp. (Nematoda: Xiphinema tidae) infesting strawberry in Himachal Pradesh, India. Trends in Biosciences. 2012; 5(2): 111-113

\section{How to cite this article:}

Anju Sharma, Satish K. Sharma, Kiran Rana and Anil Kumar Verma. 2019. Phylogenetic Analysis of $28 \mathrm{~S}$ rRNA Gene of Indigenous Xiphinema pachydermum. Int.J.Curr.Microbiol.App.Sci. 8(07): 1960-1968. doi: https://doi.org/10.20546/ijcmas.2019.807.233 